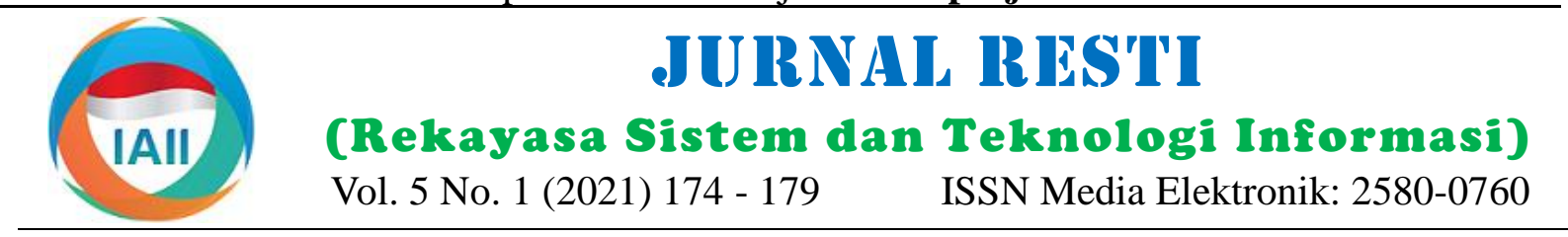

\title{
Pengenalan Aktivitas Manusia pada Area Tambak Udang dengan Convolutional Neural Network
}

\author{
M. Arfan ${ }^{1}$, Ahmad Nurjalal $^{2}$, Maman Somantri $^{3}$, Sudjadi $^{4}$ \\ 1,2,3,4 Departemen Teknik Elektro, Fakultas Teknik, Universitas Diponegoro \\ ${ }^{1}$ arfan@ft.undip.ac.id, ${ }^{2}$ anurjalan@ protonmail.com, ${ }^{3} \mathrm{~mm}$ somantri@gmail.com, ${ }^{4}$ kenungsudjadi@gmail.com
}

\begin{abstract}
Thievery is a problem that can harm theft victims. Thievery usually occurs at night when there is no supervision of goods in a location. To avoid thievery and monitor conditions in a location, CCTV (Closed-Circuit Television) cameras can be used. However, the function of CCTV camera systems is only a passive monitoring systems. In this paper, a human activity recognition is designed using CCTV cameras to produce a security system. Inputs on the recognition process are videos obtained from CCTV cameras installed in the shrimp pond. Human activity recognition that is used in this study is Convolutional Neural Network. Before the human activity recognition was carried out, the program first detected humans with the YOLO (You Only Look Once) algorithm and tracking it with the SORT (Simple Online and Realtime Tracking) algorithm. The results obtained from the human activity recognition is class labels on human objects that are tracked.
\end{abstract}

Keywords: CCTV, detection, tracking, activity pattern, convolutional neural network

\begin{abstract}
Abstrak
Pencurian pada area tambak udang merupakan permasalahan yang dapat merugikan petani. Pencurian biasanya terjadi pada malam hari ketika tidak ada pengawasan terhadap barang di suatu lokasi. Untuk menghindari pencurian dan memantau keadaan di lokasi tambak udang, maka CCTV (Closed-Circuit Television) dapat digunakan. Namun, sistem kamera CCTV hanya berfungsi sebagai sistem pemantauan pasif. Penelitian ini,merancang suatu pengenalan aktivitas manusia dengan memanfaatkan kamera CCTV sehingga menghasilkan suatu sistem keamanan. Masukan pada proses pengenalan berupa video yang diperoleh dari kamera CCTV yang dipasang di area tambak udang. Pengenalan aktivitas manusia pada penelitian ini menggunakan arsitektur Convolutional Neural Network. Sebelum pengenalan aktivitas manusia dilakukan, program terlebih dahulu mendeteksi manusia dengan algoritma YOLO (You Only Look Once) dan tracking dengan algoritma SORT (Simple Online and Realtime Tracking). Hasil yang diperoleh dari pengenalan aktivitas manusia berupa label kelas pada objek manusia yang terlacak dan deteksi manusa objek manusia yang masuk pada Kawasan tertentu. Pola deteksi objek manusia dan kawasan yang telah diberikan penanda akan memberikan informasi dugaaan pencurian pada Kawasan tambak dengan akurasi mencapai $81,03 \%$ pada beberapa pengujian.
\end{abstract}

Kata kunci: CCTV, deteksi, tracking, pengenalan aktivitas manusia, convolutional neural network

\section{Pendahuluan}

Pencurian merupakan permasalahan yang dapat merugikan korban pencurian. Berdasarkan Badan Pusat Statistik [1]. Selama periode $2011-2018$, jenis kejadian kejahatan pencurian merupakan kejahatan yang paling banyak terjadi di Indonesia, jumlahnya mencapai lebih dari 36 - 45 persen dari total kejahatan yang terjadi di berbagai wilayah Indonesia.

Penggunaan sistem kamera CCTV (Closed-Circuit Television) dapat digunakan sebagai sistem keamanan untuk memantau keadaan pada area tertentu termasuk pada tambak udang. Namun, sistem kamera CCTV hanya berfungsi sebagai sistem pemantauan pasif saja [2]. Aktivitas manusia pada area tertentu dapat dikenali menggunakan program pengenalan aktivitas manusia dengan memanfaatkan masukan berupa video dari CCTV yang ditempatkan pada area tersebut sehingga dapat menghasilkan suatu sistem keamanan cerdas.

Pengenalan aktivitas manusia adalah kemampuan untuk menafsirkan gestur tubuh atau gerakan manusia melalui sensor dan menentukan aktivitas atau tindakan manusia [3]. JST (Jaringan Saraf Tiruan) bisa digunakan untuk

Diterima Redaksi: 22-01-2021 | Selesai Revisi: 24-02-2021 | Diterbitkan Online: 28-02-2021 
berbagai masalah, mulai dari klasifikasi, optimasi, memberikan notifikasi jika terdapat objek manusia yang kompresi, peramalan (forecasting), sistem kontrol, terdeteksi pada area tertentu. sistem pendeteksian kecurangan (intrusion detection systems), dan sebagainya [4]. Convolutional neural networks, biasanya disingkat $\mathrm{CNN}$ atau ConvNet, adalah salah satu kelas deep feed-forward artificial neural networks (JST) yang banyak diaplikasikan pada analisis citra [5].

Sebelum pengenalan aktivitas manusia dilakukan, terdapat proses deteksi manusia yang menghasilkan keluaran koordinat deteksi. Jika manusia terdeteksi, tracking dilakukan pada masing-masing deteksi manusia yang ada dan menghasilkan keluaran berupa koordinat tracking dan ID tracking. Pengenalan aktivitas manusia Terdapat beberapa peneliti yang melakukan penelitian kemudian dilakukan pada masing-masing tracking yang tentang pengenalan aktivitas dengan arsitektur ada.

Convolutional Neural Network dengan melakukan deteksi objek dan tracking terlebih dahulu. Pada penelitian yang dilakukan sebelumnya, algoritma deteksi yang digunakan adalah faster R-CNN (Region Convolutional Neural Network) sedangkan algoritma tracking yang digunakan adalah distance based multitarget tracking [6]. Pada penelitian yang lain, algoritma deteksi yang digunakan adalah HOG (Histogram Oriented Gradient) dan SVM (Support Vector Machine) sedangkan algoritma tracking yang digunakan adalah Kalman tracking dan Hungarian data association [7].

Penelitian ini dilakukan untuk menghasilkan pengenalan aktivitas manusia dengan masukan berupa video CCTV yang dipasang pada area tambak udang. Namun, sebelum pengenalan aktivitas manusia dilakukan, proses deteksi manusia dan tracking terlebih dulu dilakukan. Kemudian, proses pengenalan aktivitas manusia dilakukan pada objek manusia yang ter-tracking.

Pada penelitian ini dirancang suatu pengenalan aktivitas manusia dengan menggunakan arsitektur Convolutional Neural Network yang memiliki input berupa frameframe yang berurutan. Proses pengenalan dilakukan setelah deteksi manusia dan tracking dilakukan. Proses pengenalan ini akan menghasilkan kelas label pada objek manusia yang ter-tracking. Algoritma yang digunakan untuk deteksi manusia adalah YOLO (You Only Look Once) sedangkan algoritma yang digunakan untuk tracking adalah SORT (Simple Online and Realtime Tracking). Beberapa penelitian hanya membahas deteksi objek manusia dan belum melakukan trigger pada kondisi dan keadaan kawasan tertentu. Proses pendeteksian manusia akan dikombinasikan dengan penanda objek vital pada tambak.

\section{Metode Penelitian}

\subsection{Deskripsi Sistem}

Dalam sistem yang dirancang pada penelitian ini adalah sistem yang dapat mengenali aktivitas manusia, mendeteksi, tracking, serta mengirim notifikasi jika terdapat objek terdeteksi pada area tertentu di area tambak udang. Kelas aktivitas yang akan didefinisikan adalah berjalan dan berlari. Jika terdapat aktivitas pada area tambak udang, maka sistem ini dapat memberikan output berupa prediksi aktivitas yang dilakukan dengan menggunakan Convolutional Neural Network serta
Seperti pada gambar 1, masukan dari sistem ini adalah video yang direkam oleh kamera yang dipasang untuk memantau area tambak udang. Jenis kamera yang digunakan adalah IP Camera Hikvision DS-2CD1021-I. Video yang direkam akan diolah oleh komputer. Pengolahan tersebut meliputi deteksi manusia, tracking, deteksi posisi objek (di luar kolam atau di dalam kolam), dan pengenalan aktivitas. Proses input video dilakukan oleh program dengan library OpenCV.

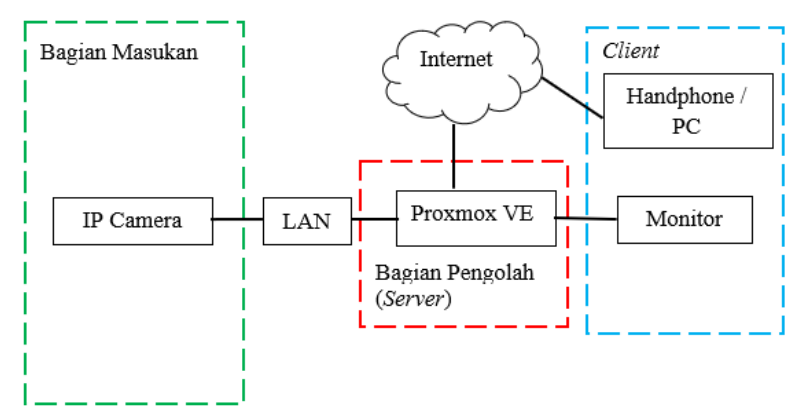

Gambar 1. Diagram blok sistem pengenalan aktivitas manusia

Sistem yang dirancang adalah sistem yang dapat mengenali aktivitas manusia, mendeteksi, tracking, serta mengirim notifikasi jika terdapat objek terdeteksi pada area tertentu di area tambak udang. Kelas aktivitas yang akan didefinisikan adalah berjalan dan berlari. Jika terdapat aktivitas pada area tambak udang, maka sistem ini dapat memberikan output berupa prediksi aktivitas yang dilakukan dengan menggunakan Convolutional Neural Network serta memberikan notifikasi jika terdapat objek manusia yang terdeteksi pada area tertentu.

Proses pertama dalam sistem adalah deteksi manusia menggunakan algoritma YOLO dengan menggunakan framework Darkflow dan library tensorflow. Algoritma YOLO terdiri dari model Convolutional Nueral Network, sehingga diperlukan training menggunakan dataset untuk kelas yang diinginkan untuk dideteksi, dalam hal ini manusia. Jika terdapat objek manusia dengan nilai prediksi lebih besar atau sama dengan threshold, maka output fungsi prediksi pada framework darkflow akan menghasilkan koordinat-koordinat deteksi.

Proses kedua adalah tracking menggunakan algoritma SORT (Simple Online and Realtime Tracking). Setiap 
deteksi manusia akan diberikan ID unik dengan kolam tambak), dan prediksi aktivitas pada masingalgoritma ini. Dengan tracking, komputer dapat masing tracking.

mengenali bahwa terdapat manusia yang sama pada frame-frame tertentu yang berurutan jika manusia 3. Hasil dan Pembahasan tersebut masih terdapat pada frame berututan tersebut berdasarkan koordinat-koordinat deteksi pada setiap frame.

Terdapat beberapa pengujian yang dilakukan pada penelitian ini. Pengujian dilakukan terhadap sistem agar dapat dianalisis. Masukan yang digunakan adalah Proses ketiga adalah pengenalan aktivitas manusia. beberapa video dengan durasi berbeda yang direkam Proses ini adalah proses akhir yang menghasilkan output dengan laju frame sebanyak 6 frame per detik. Posisi prediksi aktivitas pada setiap tracking yang ada. kamera tidak berubah pada berbagai pengujian. Pengenalan aktivitas manusia yang dirancang Pengujian deteksi manusia dan pengujian pengenalan menggunakan model Convolutional Neural Network[8]. aktivitas manusia yang dilakukan dibagi menjadi empat Arsitektur Convolutional Neural Network yang bagian, yaitu:

digunakan adalah arsitektur temporal dari Two-Stream Convolutional Networks For Action Recognition in Videos, seperti pada gambar 2. Pada penelitian ini, kelas yang akan diklasifikasi dibagi menjad dua, yaitu aktivitas berjalan dan aktivitas berlari.

1. Pengujian deteksi manusia untuk menguji tingkat akurasi deteksi manusia dengan variasi jumlah manusia.

Pada gambar 2, arsitektur CNN yang digunakan
memiliki 8 layer yang terdiri dari 5 convolution layer, 2 fully connected layer dan 1 softmax layer [9]. Fungsi aktivasi yang digunakan pada masing-masing convolution layer adalah ReLU. Algoritma optimasi yang digunakan pada penelitian ini adalah Stochastic Gradient Descent dengan parameter laju pembelajaran sebesar 10-4 dan momentum sebesar 0.9.

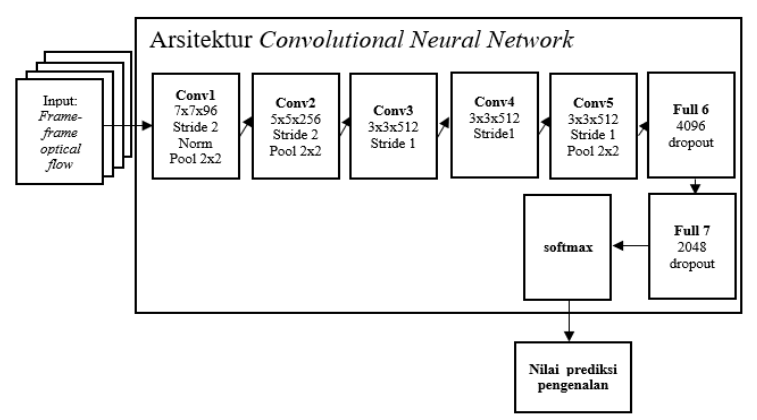

2. Pengujian aktivitas manusia untuk menguji tingkat akurasi pengenalan aktivitas manusia.

3. Pengujian pengiriman pemberitahuan dilakukan dengan mengirimkan teks melalui email kepada penerima dari penyedia layanan email yang berbedabeda.

4. Pengujian pengiriman citra terdeteksi di area kolam ke media server.

\subsection{Pengenalan Manusia}

Pengujian deteksi manusia bertujuan untuk mengetahui kinerja deteksi manusia berdasarkan parameter yang telah ditentukan. Pengujian deteksi manusia yang dilakukan berupa pengujian variasi jumlah manusia terhadap kinerja deteksi manusia pada kondisi mode kamera dengan siang dan mode kamera malam.

Gambar 3 merupakan contoh deteksi manusia pada siang hari pada area kolam. Gambar 4 merupakan contoh deteksi manusia pada malam hari dengan IR-cut filter pada kamera yang menyala.

Gambar 2. Arsitektur CNN untuk pengenalan aktivitas manusia [9]

Data masukan pada model CNN adalah array dua dimensi dengan ukuran 224x224 yang merupakan tumpukan dari 5 frame berurutan dari objek manusia yang terdeteksi dan ter-tracking yang telah diproses menggunakan metode optical flow][10]. Masing-masing frame memiliki dua kanal warna yang terdiri dari satu kanal warna untuk komponen horizontal dan satu kanal warna untuk komponen vertikal, sehingga data masukan

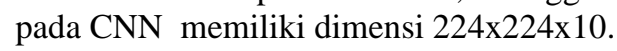

Penulisan program pada semua proses menggunakan bahasa pemrograman Python. Penulisan program untuk membuat model Convolutional Neural Network pada program deteksi manusia dan pengenalan aktivitas manusia dibuat dengan library tensorflow [11] dan dijalankan menggunakan GPU Nvidia GeForce $1050 \mathrm{Ti}$.

Keluaran keseluruhan yang dapat dihasilkan dengan sistem ini adalah koordinat deteksi, ID tracking, koordinat tracking, posisi (di luar kolam atau di dalam

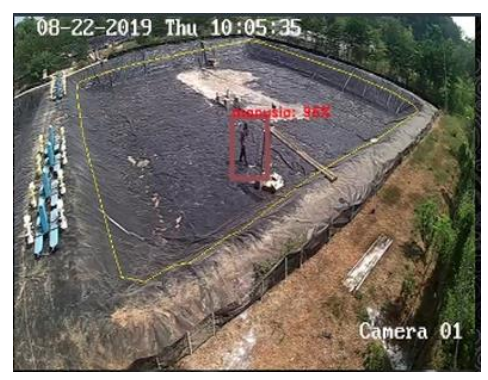

Gambar 4. Contoh deteksi manusia siang hari

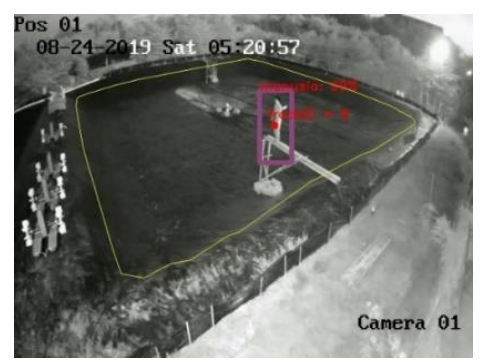

Gambar 5. Contoh deteksi manusia malam hari 


\subsection{Pengujian akurasi perhitungan jumlah manusia}

Pengujian dilakukan dengan 4 kali percobaan dengan variasi jumlah manusia. Pengujian ini bertujuan untuk mengetahui akurasi parameter yang digunakan terhadap kinerja deteksi. Terdapat 2 variasi jumlah manusia pada video yang digunakan, yakni video dengan berisi 1 dan 2 orang manusia.

Manusia dianggap terdeteksi bila program menampilkan persegi yang menandakan bahwa program mendeteksi manusia. Akurasi deteksi manusia yang diuji pada beberapa video tersebut ditentukan menggunakan parameter true positive, true negative, false positive, dan false negative. True positive (TP) adalah saat program mendeteksi manusia saat manusia tersebut ada. True negative (TN) adalah saat program tidak mendeteksi manusia saat manusia tersebut tidak ada. False positive (FP) adalah saat program mendeteksi manusia saat manusia tersebut tidak ada. False negative (FN) adalah saat program tidak mendeteksi manusia saat manusia tersebut terlihat [12]. Akurasi dapat ditentukan sebagai berikut:

$$
\text { Akurasi }=\frac{T P+T N}{T P+F P+F N+T N}
$$

Data pengujian yang diambil adalah manusia yang memiliki jarak antara 1.5 sampai 10 meter dari kamera dengan frame yang berurutan. Gambar 6 dan gambar 7 adalah gambar pengujian variasi jumlah manusia terhadap kinerja deteksi manusia.

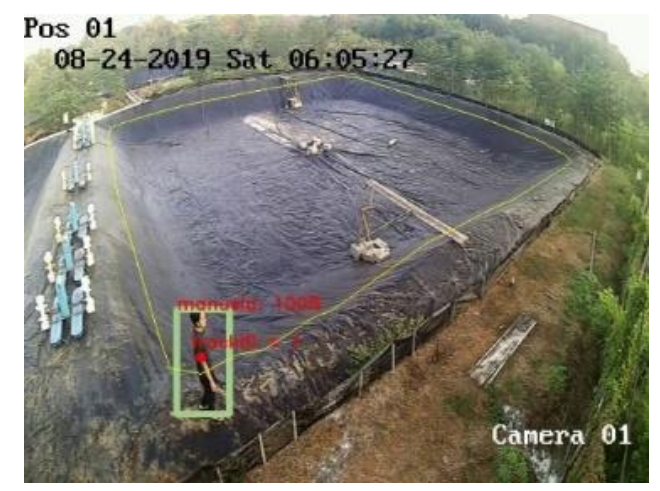

Gambar 6. Contoh variasi deteksi 1 manusia

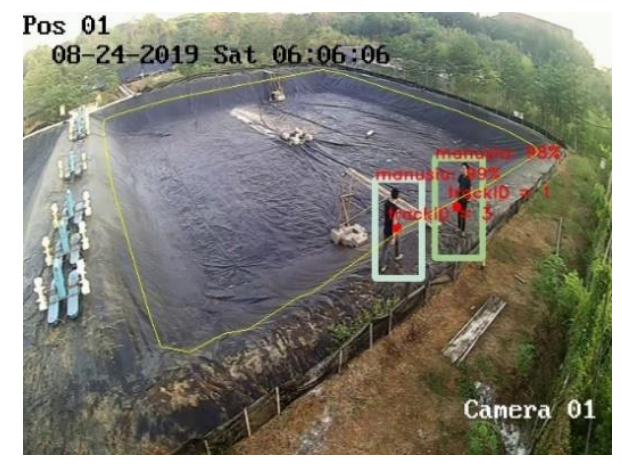

Gambar 7. Contoh variasi deteksi 2 manusia
Berdasarkan tabel 1, akurasi deteksi yang didapatkan cukup baik pada percobaan 1,2, dan 4 dengan nilai akurasi lebih dari 70 persen. Sedangkan pada nilai akurasi pada percobaan 3 hanya 58,4 persen. Ini dikarenakan kondisi luar ruangan yang dinamis. Dari keempat data pengujian, didapatkan nilai rata-rata akurasi sebesar 74,3 persen.

Tabel 1. Hasil pengujian variasi deteksi jumlah manusia

\begin{tabular}{ccccccc}
\hline Percobaan & $\begin{array}{c}\text { Jumlah } \\
\text { Manusia }\end{array}$ & $T P$ & $F N$ & $T N$ & $F P$ & $\begin{array}{c}\text { Akurasi } \\
(\%)\end{array}$ \\
\hline 1 & 1 & 55 & 13 & 0 & 0 & 80,88 \\
2 & 1 & 32 & 12 & 8 & 0 & 76,92 \\
3 & 2 & 66 & 47 & 0 & 0 & 58,4 \\
4 & 2 & 141 & 33 & 0 & 0 & 81,03 \\
\hline
\end{tabular}

3.3. Pengujian pengenalan aktifitas manusia

Pengujian pengenalan aktivitas manusia dilakukan dengan menggunakan confussion matrix. Confusion matrix merupakan salah satu metode yang dapat digunakan untuk mengukur kinerja suatu metode klasifikasi. Pada pengujian ini, variabel deteksi dan tracking diabaikan, jadi Pada dasarnya confusion matrix mengandung informasi yang membandingkan hasil klasifikasi yang dilakukan oleh sistem dengan hasil klasifikasi yang seharusnya. Tabel confussion matrix seperti pada gambar 8 terdiri dari hasil prediksi dan hasil sebenarnya . Nilai prediksi merupakan nilai yang disajikan berdasarkan kolom, sedangkan nilai sebenarnya adalah data yang disajikan berdasarkan baris.

Tabel 2 menunjukkan tingkat akurasi klasifikasi dua kelas yang berbeda, yaitu berjalan dan berlari. Dara gambar tersebut, sampel yang diuji berjumlah 10 yang terdiri dari data berjalan dan berlari masing-masing 5 . Terdapat 5 data uji berjalan yang digunakan untuk dilakukan penilaian akurasi. Dari 5 data tersebut, terdapat 4 data yang terklasifikasi dengan benar dan 1 data yang terklasifikasi salah. Pada data uji berlari, terdapat 5 frame yang digunakan untuk penilaian akurasi. Dari 5 frame tersebut, terdapat 4 data uji yang terklasifikasi dengan benar dan 1 data uji yang terklasifikasi dengan salah. Kesalahan pada klasifikasi diperoleh karena kondisi lingkungan yang dinamis dan data latih yang kurang bervariasi. Dari kedua video uji, dapat diketahui bahwa akurasi pengenalan aktivitas manusia bernilai 80 persen.

Pengujian pengenalan aktivitas manusia dilakukan setelah proses deteksi dan tracking berhasil dan telah mencapai frame ke 5 setelah tracking. Oleh karena itu, data uji diambil dari frame-frame video yang telah berhasil dideteksi dan ditracking. Jumlah data uji berupa video yang terdapat objek manusia yang melakukan aktivitas berlari dan berjalan seperti pada gambar 8 dan gambar 9. 


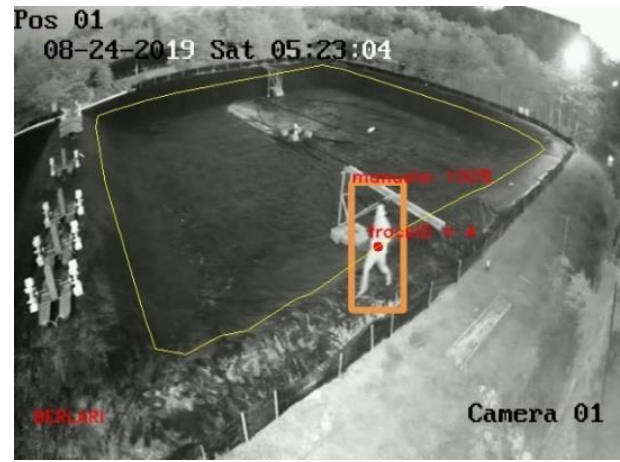

Gambar 8. Hasil pengenalan aktivitas berlari

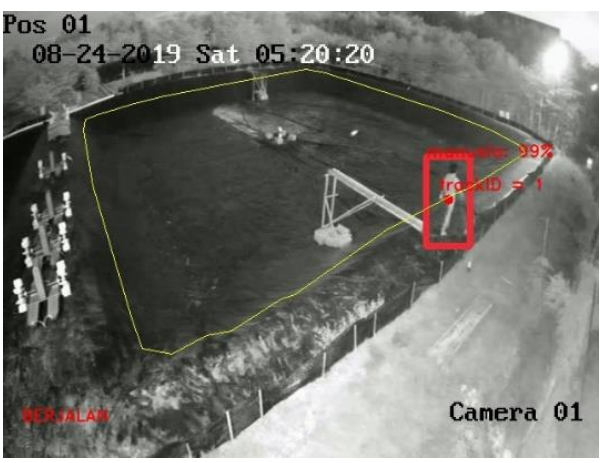

Gambar 9. Hasil pengenalan aktivitas berjalan

\subsection{Pengujian pengiriman notifikasi}

Pengujian pengiriman pemberitahuan dilakukan untuk mengetahui kinerja program dalam mengirimkan pemberitahuan. Pengujian dilakukan dengan cara mengirimkan email dari alamat email asal kepada alamat email yang akan dituju. Email pengirim pemberitahuan telah dilakukan konfigurasi agar dapat mengizinkan sambungan dengan kondisi yang tidak aman.

Pengujian dilakukan dengan menjalankan program dengan video uji yang frame-framenya memiliki objek manusia yang berada di luar dan di dalam garis polygon, yaitu pada kolam tambak. Email tujuan memiliki domain email yang berbeda seperti gmail, protonmail,, dan outlook. Pada pengujian, email dikirim kepada 5 alamat yang berbeda. Saat terdapat objek yang terdeteksi dan terlacak pada area kolam, Pemberitahuan akan dikirimkan melalui email sehingga diketahui oleh pengelola kolam.

$\begin{aligned} \text { tanggal: } & 24 \text { Agu } 201905.38 \\ \text { subjek: } & \text { PERINGATAN } \\ \text { dikirim oleh: } & \text { gmail.com } \\ \text { ditandatangani oleh: } & \text { gmail.com } \\ \text { keamanan: } & \text { a Enkripsi standar (TLS) Pelajari selengkapnya } \underline{\underline{a}} \\ \text { D: } & \text { Penting terutama karena Anda sering membaca pesan dengan label ini. }\end{aligned}$

Gambar 10. Hasil email yang diterima alamat email

Peringatan diberikan jika terjadi aktfitas yang sudah dilatihkan Dari pengukuran tingkat akurasi klasifikasi dua kelas sebelumnya. Peringatan akan dikirimkan melalui email
yang berbeda, yaitu berjalan dan berlari. Dara gambar sehingga memberikan notifikasi pada pengguna layanan. tersebut, sampel yang diuji berjumlah 20 tangkapan video yang terdiri dari data berjalan sebanyak 10 video dan berlari sebanyak 10 video. Proses deteksi memerlukan 5 frame untuk mengenali aktivitas manusia. Pada uji berjalan dari 10 data tersebut, terdapat 8 data yang terklasifikasi dengan benar dan 2 data yang terklasifikasi salah. Pada data uji berlari, dapat dikenali 5 frame untuk penilaian akurasi. Dari 10 data video tersebut, terdapat 8 video data uji yang terklasifikasi dengan benar dan 2 video data uji yang terklasifikasi dengan salah. Kesalahan pada klasifikasi diperoleh karena kondisi lingkungan yang dinamis dan data latih yang kurang bervariasi. Dari kedua video uji, dapat diketahui bahwa akurasi pengenalan aktivitas manusia bernilai 80 persen. Setelah deteksi manusia diperlukan area marker pada objek vital. Pada gambar terlihat garis kuning yang mengelilingi area tambak., jika terdapat objek manusia yang menembus batas tersebut maka sistem akan memberikan notifikasi pada pengelola tambak. Area yang diberikan marker merupakan area terbatas yang hanya diakses oleh pengelola tambak sehingga perlu dilakukan pengawasan secara khusus.

\begin{tabular}{lcc}
\multicolumn{2}{c}{ Tabel 2. Tabel Confussion } & \multicolumn{2}{c}{ Matriks } \\
\hline & Aktual: Berjalan & Aktual: Berlari \\
\hline Prediksi Berjalan & 8 & 2 \\
Prediksi Berlari & 8 & 2 \\
\hline
\end{tabular}

\section{PERINGATAN, Manusia Terdeteksi berlari Inbox}

(A) Peringatan

@gmail.com 05:16

Gambar 11. Hasil email notifikasi aktivitas berlari

\subsection{Pengujian pengiriman file citra ke media server}

Pengujian pengiriman citra ke media server dilakukan untuk mengetahui kinerja program dalam mengirimkan file citra ke media server. Pengujian dilakukan dengan cara mengirimkan 5 file citra yang ter-tracking dengan syarat berada di dalam area kolam. Pengiriman berasal dari server ke media server.

Dalam pengiriman membutuhkan beberapa sumberdaya jaringan dalam mengirimkan parameter. Dengan melakukan pengukuran akan diketahui kehandalan dari jaringan dan protocol pengiriman pada aplikasi dan jaringan. Dari pengujian akan diketahui tingkat keberhasilkan pelaporan dan pengiriman citra yang akan disimpan di dalam database.

Tabel 3 adalah tabel hasil pengujian pengiriman file citra ke media server. Jumlah frame dikirimkan berbedabeda, yaitu 1,3 dan 5 sesuai dengan jumlah tracking yang berhasil dan berada pada area kolam. Terlihat semua percobaan berhasil dilakukan dengan akurasi sempurna. 
Tabel 3. Hasil pengujian pengiriman file citra ke media Daftar Rujukan

\begin{tabular}{|c|c|c|c|}
\hline Percobaan & $\begin{array}{c}\text { Jumlah frame } \\
\text { terkirim }\end{array}$ & $\begin{array}{c}\text { Jumlah frame } \\
\text { diterima }\end{array}$ & Keterangan \\
\hline 1 & 1 & 1 & Terkirim \\
\hline 2 & 3 & 3 & $\begin{array}{l}\text { Diterima } \\
\text { Terkirim } \\
\text { Diterima }\end{array}$ \\
\hline 3 & 5 & 5 & $\begin{array}{l}\text { Terkirim } \\
\text { Diterima }\end{array}$ \\
\hline 4 & 8 & 8 & $\begin{array}{l}\text { Terkirim } \\
\text { Diterima }\end{array}$ \\
\hline 5 & 10 & 10 & $\begin{array}{l}\text { Terkirim } \\
\text { Diterima }\end{array}$ \\
\hline
\end{tabular}

\section{Kesimpulan}

Pada pengujian deteksi manusia, rata-rata akurasi jumlah manusia sebesar 74,3 persen (tabel 1) dengan penggabungan variasi jumlah manusia sebanyak 1 orang dan 2 orang. Sedangkan untuk pengujian akurasi pengenalan aktivitas manusia dengan data uji 20 video didapatkan akurasi bernilai 80 persen (tabel 2). Jika [7] objek manusia memasuki area marker berupa garis kuning yang mengelilingi kolam maka sistem akan mengaktifkan pemberitahuan yang dikirimkan melalui email dan menampilkan dilayar monitor pengelola tambak. Apabila terdapat hasil pengenalan aktivitas pada objek dan menembus area marker tersebut, maka email dan layar monitor pengelola tambak akan dikirimkan pesan peringatan beserta hasil tangkapan layar aktivitas manusia.
Badan Pusat Statistik, "Statistik Kriminal 2019," 2019. [Online].

Available:https://www.bps.go.id/publication/2019/12/12/66c0 114edb7517a33063871f/statistik-kriminal-2019.html.

[2] W. Huang and S. Li, "Understanding human activity patterns based on space-time-semantics," ISPRS J. Photogramm. Remote Sens., vol. 121, pp. 1-10, 2016, doi: 10.1016/j.isprsjprs.2016.08.008.

[3] V. Gajjar, A. Gurnani, and Y. Khandhediya, "Human Detection and Tracking for Video Surveillance A Cognitive Science Approach," arXiv1709.00726v1 [cs], pp. 2805-2809, 2017, doi: 10.1109/ICCVW.2017.330.

L. Maczyta, P. Bouthemy, and O. Le Meur, "CNN-based temporal detection of motion saliency in videos," Pattern Recognit. Lett., vol. 128, pp. 298-305, Dec. 2019, doi: 10.1016/j.patrec.2019.09.016.

[5] Suyanto, Machine Learning Tingkat Dasar Dan Lanjut". Informatika Bandung, 2018.

[6] M. Zhang, C. Gao, Q. Li, L. Wang, and J. Zhang, "Action detection based on tracklets with the two-stream CNN," Multimed. Tools Appl., vol. 77, no. 3, pp. 3303-3316, 2018, doi: 10.1007/s11042-017-5116-9.

A. Farouk Khalifa, E. Badr, and H. N. Elmahdy, "A survey on human detection surveillance systems for Raspberry Pi," Image Vis. Comput., vol. 85, pp. 1-13, 2019, doi: 10.1016/j.imavis.2019.02.010.

[8] Y. Xiang, Z. He, Q. Liu, J. Chen, and Y. Liang, "Autofocus of whole slide imaging based on convolution and recurrent neural networks," Ultramicroscopy, vol. 220, no. August 2020, p. 113146, 2021, doi: 10.1016/j.ultramic.2020.113146.

[9] K. B. Meena and V. Tyagi, "Distinguishing computer-generated images from photographic images using two-stream convolutional neural network," Appl. Soft Comput., vol. 100, p. 107025, 2021, doi: 10.1016/j.asoc.2020.107025.

[10] J. Gu et al., "Recent advances in convolutional neural networks," Pattern Recognit., vol. 77, pp. 354-377, 2017, doi: 10.1016/j.patcog.2017.10.013.

[11] S. Masood, A. Rai, A. Aggarwal, M. N. Doja, and M. Ahmad, "Detecting distraction of drivers using Convolutional Neural Network," Pattern Recognit. Lett., vol. 0, pp. 1-7, 2018, doi: 10.1016/j.patrec.2017.12.023.

[12] M. Shahverdy, M. Fathy, R. Berangi, and M. Sabokrou, "Driver behavior detection and classification using deep convolutional neural networks," Expert Syst. Appl., vol. 149, p. 113240, 2020, doi: 10.1016/j.eswa.2020.113240. 